\title{
Inpretation of Associative Data as a Methodogical Issue of Psycholinguistics
}

\author{
Vera A. Pishchalnikova \\ Moscow State Linguistic University \\ 38 Ostozhenka str., Building 1, Moscow, 119034, Russia
}

\begin{abstract}
Associative experiments uncover people's active attitude to the world represented by language means that determines their relevant strategies of verbal activity and mediates the specifics of their world conceptualization. A word's associative field modeled on the basis of experimental data is a psychological structure of a word's content that is relevant for native speakers. Associative meaning distinguished via the analysis of distribution of reactions to a stimulus word proves to be an effective method of discovering emerging trends in the change of word meanings. The author researches the issue of data interpretation in associative experiments. Despite the long history of usage, the notion "associative field" and the correlation of stimulus and reaction are often interpreted in different ways because, firstly, they model the most complex processes of speech activity; secondly, most of suggested typologies of associates do not have a common systematization criterion, which hinders the usage of such classifications in research practice and sometimes leads to an ambiguous interpretation of associative data. Therefore, the author argues that classifications of associates should be developed depending on: (1) characteristics of psycholinguistic/linguistic object researched through an associative experiment; (2) isomorphism of speech and the activity it accompanies; (3) characteristics of mental supports in the cognitive process; (4) the way of representation of these supports. Such criteria of classification require an analysis of the correlation between stimulus and reaction as a unit of association. This correlation is a separate speech act where the stimulus is a motive producing the reaction and the associate expresses the author's communicative intention. This helps to establish motives of associating and thus acquire a more veracious database for modelling different components of speech activity and its overall production/ comprehension processes. Besides, this approach justifies the principles of worldview modelling. The author presents theoretical and methodological grounds for an effective analysis of associates on the basis of a psycholinguistic object defined by several parameters: strategy of association, dominant psychological function of a language sign that realizes the strategy and the motive of activity explicated in associates.
\end{abstract}

Keywords: stimulus, reaction, associate, associative experiment, associative field, nucleus of field, periphery of field, classification, worldview, modelling

\section{For citation:}

Pishchalnikova, Vera A. (2019). Interpretation of Associative Data as a Methodogical Issue of Psycholinguistics. Russian Journal of Linguistics, 23 (3), 749-761. doi: 10.22363/2312-9182-2019-233-749-761. 


\title{
Интерпретация ассоциативных данных как проблема методологии психолингвистики
}

\author{
В.А. Пищальникова \\ Московский государственный лингвистический университет \\ ул. Остоженка, 38, стр. 1, Москва, 119034, Россия
}

\begin{abstract}
Аннотация
Ассоциативный эксперимент выявляет деятельностное отношение человека к миру, представленное языковыми средствами, которое детерминирует актуальные для индивида стратегии вербальной деятельности и опосредованно - специфику концептуализации мира. Ассоциативное поле слова, моделируемое по данным эксперимента, представляет психологическую структуру содержания слова, актуальную для носителей языка. Ассоциативное значение, выявляемое посредством анализа дистрибуции реакций на слово-стимул, оказывается одновременно эффективным средством обнаружения намечающихся тенденций в изменении значения слова. Автор статьи исследует проблему интерпретации данных ассоциативного эксперимента. Несмотря на давние традиции использования, понятие «ассоциативное поле» и соотношение стимул - реакиия трактуются по-разному, поскольку, во-первых, созданы для анализа сложнейшего феномена - речевой деятельности. Во-вторых, в большинстве предложенных типологий ассоциатов нет единого критерия их систематизации, что усложняет применение таких классификаций в исследовательской практике и приводит, в частности, к неоднозначной интерпретации ассоциативных данных. Поэтому автор статьи аргументирует положение, согласно которому классификации ассоциатов должны выстраиваться (1) в зависимости от моделируемых свойств психолингвистического / лингвистического объекта, который исследуется с помощью ассоциативного эксперимента, (2) от изоморфности речевой деятельности той, которую она сопровождает, (3) от характера ментальных опор в познавательном процессе, (4) от способа вербальной репрезентации этих опор. Такие критерии классификации требуют анализировать в качестве единицы ассоциирования соотношение стимула и реакции, которое представляет собой единое речевое действие, где стимул становится мотивом порождения высказывания, а ассоциат выражает коммуникативное намерение автора. Это позволяет установить мотивы ассоциирования и, таким образом, получить более достоверную базу данных для моделирования различных компонентов речевой деятельности и процесса ее продуцирования / восприятия в целом. Кроме того, такой подход обосновывает принципы моделирования образа мира. Автор представляет теоретико-методологическое основание позиции, согласно которой эффективный анализ ассоциатов возможен на основе психолингвистического объекта, заданного несколькими параметрами: стратегией ассоциирования, доминирующей психологической функцией языкового знака, реализующего стратегию, мотивом деятельности, эксплицированным в ассоциатах.
\end{abstract}

Ключевые слова: стимул, реакиия, ассоциат, ассоџиативный эксперимент, ассочиативное поле, ядро поля, периферия поля, классификация, образ мира, моделирование

\section{Для цитирования:}

Пищальникова В.А. Интерпретация ассоциативных данных как проблема методологии психолингвистики // Russian Journal of Linguistics. 2019. Т. 23. No 3. С. 749—761. doi: 10.22363/23129182-2019-23-3-749-761.

\section{1. Введение. Постановка проблемы}

Описание психического процесса ассоциирования, начатое в отечественной лингвистике работами А.А. Леонтьева (Леонтьев 1969), до сих пор представляет одну из самых сложных теоретических проблем и требует серьезной методологической проработки, тем более что эксперимент является одним из действенных 
способов обнаружения глубинных ассоциативных связей слова и потому может обслуживать разные методики анализа его значения. В ассоциативном эксперименте проявляется способ актуализации слова как предмета деятельности, представленный в стратегии ассоциирования, что позволяет установить предпочтения индивида в способах действования со словом и опосредованно - специфику его образа мира. Ассоциативный эксперимент позволяет регистрировать психологически актуальные смыслы, реализуемые носителями языка в речевых произведениях, в том числе и в соотношении стимул - реакция, основанном на предикации (Miller, Johnson-Laird 1976). Поэтому ассоциативный тезаурус - это и способ фиксации языковой способности носителя языка, «вероятностного мира языковой личности» (Караулов 1999:7), и база для установления универсального и индивидуального в его организации. Следовательно, на основе психолингвистического анализа ассоциативного поля возможно обнаружение мотивов речевой деятельности индивида и интерпретация специфики его ассоциативно-вербальной сети. Однако то, что соотношение стимула и реакции предикативно, часто упоминается, не находя применения в анализе реальных массивов ассоциатов. Экспериментальные исследования показывают также, что любое слово как предмет речевой деятельности обладает некоторым эмоциональным значением (Кинцель 1998), но эта «слабая эмоциональность», будучи важной с точки зрения психологического содержания речи и определения способов оперирования словом, может быть выделена только при анализе ассоциатов. Ассоциативные реакции фиксируют, кроме того, и интуитивные различия между словами, имеющими одинаковые или сходные области референции, например, стилистические. Поэтому эффективность ассоциативного эксперимента в изучении значения слова трудно переоценить.

Известно, что ассоциативное поле (далее АП. - В.П.) того или иного словастимула рассматривается в отечественных психолингвистических исследованиях не только как (1) фрагмент вербальной памяти человека, но и как (2) фрагмент образа мира «усредненного» носителя той или иной культуры. Такая позиция представлена, например, рядом работ (Тарасов 1993; Уфимцева 2011) создателей Русского ассоциативного словаря [РАС 2002]. Первое сомнений не вызывает, если акцентировать, что ассоциативное поле - модель фрагмента памяти, поскольку соотношение стимул - реакция, в полном соответствии с теорией речевой деятельности, рассматривается как речевое действие / операция. Второе же - установление содержательной аналогии между компонентами модели вербальной памяти и фрагментами образа мира - едва ли можно принять безоговорочно.

В свое время нами были отмечены некоторые проблемные вопросы методики проведения и интерпретации данных свободного ассоциативного эксперимента с целью сравнения «содержания образов мира» носителей разных лингвокультур и интерпретации его данных (Пищальникова 2007). Было отмечено, что, во-первых, в экспериментальных анкетах зачастую объединяются разные, хотя и соотносимые по значению, лексемы, что недопустимо в силу неодинаковых ассоциативно-вербальных связей слов в сопоставляемых языках. Кроме того, едва ли вообще возможно предполагать, что одна и та же лексема репрезентирует одно и то же ментальное образование у носителей даже одной лингвокультуры, по- 
скольку экспериментально доказано, что определенное слово может оказаться средством доступа к очень разным ментальным содержаниям (Залевская 2005).

Во-вторых, ассоциаты представляют семантические компоненты слов и могут лишь свидетельствовать о функциональном единстве семантических и ассоциативных характеристик слов (Леонтьев 1969), но вопрос об их ассоциативном содержании («образе», стоящем за словом) всегда остается открытым. Состав семантических полей лексем-стимулов, как правило, определяется на основе имеющихся лексикографических источников, но при этом нельзя отождествлять два вида исследовательских конструктов - семантическое поле и ассоциативное поле: они не изоморфны, поскольку ассоциативное поле не основывается на системных отношениях лексических единиц языка. Однако отождествление этих двух видов моделей позволяет некоторым исследователям устанавливать тождество ассоциативного поля как «фрагмента вербальной памяти человека» и «образа мира того или иного этноса, отраженного в сознании» (Медведева 2005: 86). Эта методологическая ошибка - следствие неразграничения (1) феномена памяти и модели памяти и (2) забывания того, что, по словам Л.С. Выготского, смысловой «мир» личности образуется вследствие эффективного действования с инструментами иных «миров», например, языка. И этот характер действования с инструментом (языком) в ассоциативном эксперименте опосредует содержание ассоциации, а значит не позволяет устанавливать прямые зависимости между значением словаассоциата и содержанием стоящего за ним ментального образования.

Вербальные ассоциации, повсеместно служащие материалом для суждения о содержании сознании, отражают прежде всего ассоциативные связи лексических единиц. Они только указывают на лексическую единицу, как-то соотносимую с ментальным содержанием. Задача психолингвиста - определить характер и специфику этого соотношения, т.е. установить характер действования со словом, определить, каким способом в связи стимул - ассоциат отражается превращение одной формы психологического значения в другую - языковую. На деле же анализ АП практически всегда производится с опорой на лексикографические источники, что искажает отношения ассоциатов и не выявляет специфики ассоциативных значений.

Сказанное не позволяет эффективно использовать и классификацию ассоциатов как прием анализа значения слова. А между тем исследования последних лет показали, что, опираясь на группировки ассоциатов, можно моделировать не только структуру, но и динамику значения отдельных содержательных компонентов слова и прогнозировать пути их изменения (см., например: Панарина 2017; Шевченко 2018; Хлопова 2018). Так, в перечисленных работах экспериментально доказано, что семантический сдвиг в психологической структуре значения начинается с изменения эмоционально-оценочного компонента содержания, изменения, имеющего градуальный характер: четких границ между этапами развития значения нет, но каждый из них характеризуется специфическими признаками, обусловленными закономерностями осуществления интеллектуальной и предметной деятельности в конкретных социально-коммуникативных условиях (например, 
изменение содержания прецедентных имен Сусанин, Пушкин, Цезарь, Наполеон). Хотя пути развития такого сдвига принципиально различны, эмоционально-оценочный компонент, представленный в системе ассоциатов со все возрастающей частотностью, с течением времени располагается всё ближе к ядру значения. При этом лексикографические источники не фиксируют и не могут зафиксировать эту динамику. (Для более точной констатации эмоционального содержания стимула в свое время было предложено верифицировать данные свободного ассоциативного эксперимента разными видами шкалирования.) Развивая подобные исследования, необходимо определить принципы группировки ассоциатов, которые позволили бы установить основания структурной аналогии лексического и ассоциативного значений слов.

\section{2. Проблема классификации ассоциатов}

Детальный анализ классификаций разного типа осуществлен Е.И. Горошко, которая условно разделяет существующие типологии на лингвистические, психологические, логические и «смешанные» и полагает, что «построение некой идеальной классификации ассоциаций, основанной на некоем непротиворечивом принципе, невозможно и не нужно» (Горошко 2001 textology.ru〉razdel.aspx?ID=38). C таким положением трудно согласиться: возможно, «идеальная» классификация ассоциатов и не нужна, но каждая исследовательская задача требует систематизации ассоциативных данных, и принципы такой систематизации должны быть четко определены и непротиворечивы хотя бы в рамках конкретного исследования. В противном случае исследователь получит несистемную, противоречивую, а значит научно неэффективную картину интерпретации ассоциатов, демонстрирующую искажение реальной картины ассоциирования. Неэффективность такого подхода усиливается и тем, что в этом случае не остается места для анализа единичных ассоциатов, которых, как правило, большинство в АП. Но совокупность именно единичных ассоциатов, представляющих личностные смыслы, актуализированные вербальным стимулом, позволяет обнаружить потенциильные возможности сочетаемости слова-стимула и прогнозировать на их основе пути развития значения слова. При этом значение понимается как существенно нестабильное психологическое образование, способное возникать только в конкретной речемыслительной деятельности человека. В психолингвистике личностный смысл, вслед за Л.С. Выготским, понимается как актуальная для индивида в рамках данной конкретной деятельности, в том числе вербальной, значимость предмета деятельности, которым может быть предмет, действие, событие и пр. Она детерминируется системой психологических факторов, что объясняет участие «соматического компонента» в формировании значения (см. корпореальную семантику как направление в исследовании значений (Залевская 2004; Пищальникова 2007; Пищальникова, Сонин 2017) и интеграцию разных условий смыслообразования подчинением функциональной смысловой доминанте. Поэтому один и тот же предмет может быть субъективно значимым в структуре разных деятельностей и, следовательно, порождает разные личностные смыслы. Если учитывать эти положения 
общей теории деятельности, исследование единичных ассоциаций становится важным методологическим принципом: именно функциональная значимость смысловых компонентов, понятийных и непонятийных, объясняет, на наш взгляд, принципиальную изменчивость значения. Кроме того, в ассоциировании проявляется способ возникновения личностных смыслов, проясняющий не только характер связи слов в ассоциативно-вербальной сети индивида, но и мотивацию последнего, что чрезвычайно важно для определения тенденций развития лексической семантики.

Однако, понимая, что процесс ассоциирования в высшей степени субъективен, психолингвист должен, классифицируя реакции, обнаружить в соотношении стимула и реакции такие параметры, которые проявляются как существенные независимо от целей, задач и даже содержательного характера ассоциатов.

И тогда ассоциативное поле действительно может интерпретироваться как система компонентов, в которой каждый элемент фиксирует личностный смысл, так или иначе соотносимый с психологическим значением, актуализируя субъективные ассоциативные связи со словом как предметом деятельности. При этом степень операционализации каждого ассоциата определяется его частотностью, а аксиологическая маркированность ассоциата свидетельствует о значимости для индивида смысла, стоящего за вербальной реакцией.

В свое время мы представили модель рассредоточенной репрезентации личностного смысла (Пищальникова 1991: 9), в соответствии с которой слово как интегратор всего психологического содержания, стоящего за ним, в условиях конкретной речевой деятельности позволяет представить актуальный для индивида смысл, в том числе и слабо дифференцированный. При этом все структурные компоненты ассоциативного поля слова, как ядерные, так и периферические, могут быть функционально важными для понимания речевого произведения. В ассоциативном эксперименте, как правило, в силу временных ограничений на оперирование стимулом периферийные ассоциативные и зависимые эмоциональные связи не актуализируются, поэтому можно полагать, что на активацию потенциальных ассоциативных связей влияет именно структура значения слова-стимула. Чтобы в известной степени «деактуализировать» последнее, в анкету включаются словадистракторы (фоновые стимулы), что позволяет выявлять содержание не изолированного слова, а слова, включенного в высказывание (в отношения предикации).

Некоторые исследователи предлагают делить ассоциаты «по критерию языкового уровня, на котором происходит ассоциирование» (Степыкин 2017: 72), но дело в том, что реально ассоциации возникают не в связи с языковым уровнем - у носителя языка может вообще не быть представления об уровневой (и любой другой) системе языка. Конечно, исследователь может распределить весь массив ассоциатов по языковым уровням, но это не обнаружит психологически актуального содержания, представленного в паре стимул - реакция, и не приблизит нас к пониманию характера связей лексем в ассоциативно-вербальной сети.

Сказанное актуализирует ряд методологических проблем. Так, понятия «ассоциация», «ассоциативная связь» предполагают возможность (1) анализа стратегии 
ассоциирования, (2) содержания реакции, (3) соотношения стимул - реакция как речевого действия, как акта предикации, при этом в рамках теории речевой деятельности именно последнее значимо теоретически и продуктивно для понимания речевого произведения, поскольку внешне одна и та же реакция, рассмотренная в указанном соотношении, может свидетельствовать о разных стратегиях и разных мотивах деятельности индивидов. К сожалению, в подавляющем большинстве отечественных психолингвистических исследований, в основе которых лежит свободный ассоциативный эксперимент, устанавливается содержание слова-реакции на основе лексикографического описания его значения (см., например: Федченко 2005; Евсеева 2005; Медведева 2005; Дурандина 2006; Степанова 2006; Навильникова 2008 и др). Как правило, исследователи не выясняют, каким образом в отношениях стимул-реакция проявляются коммуникативные операции различного типа, модальные оценки и т.д., что позволило бы судить о структуре и сущности речевой деятельности вообще.

Не разграничиваются ассоциативные реакции, относящиеся к области референции слова-стимула, и «истинные» ассоциации (первые, как правило, отражают ту или иную смежность словесных форм, вторые - внутренние психические состояния, порождающие реакции), поскольку пока не выработаны процедуры отделения этих содержаний в вербальной реакции, где, как правило, пересекаются компоненты различной модальности. Поэтому необходимым методологическим шагом, в развитие идей А.А. Леонтьева о соотношения стимула и реакции как речевого действия, на наш взгляд, является теоретическое осмысление сущности этого соотношения и экспериментальная проверка его специфики (или отсутствия таковой) по сравнению с другими речевыми действиями. Вербальный стимул формирует мотив высказывания реципиента, а ассоциат выражает его коммуникативное намерение. В этом случае с помощью данных ассоциативного эксперимента можно моделировать содержательную структуру психологически значимых для индивида смыслов и процессы их изменения и далее использовать полученные результаты для моделирования фрагментов ассоциативно-вербальной сети: «Ассоциативный словарь... - это еще не речь, но он являет язык в его предречевой готовности, обнажая сокровенный, скрытый от прямого наблюдения способ „держания“ языка в памяти его носителя, приоткрывая таинственную завесу над святая святых, над тем, как устроена языковая способность человека, человека говорящего и понимающего» (Караулов 2000: 750).

\section{3. Соотношение стимул - реакция как специфический психолингвистический объект}

По А.А. Леонтьеву, одна и та же языковая единица в структуре конкретного речевого действия может выполнять разные функции, реализуя цели речевой деятельности: обозначение свойств, качеств и функций объекта, указание через данный объект на другой, обозначение культурного содержания и пр. Именно цель речевой деятельности определяет вариативность содержания, стоящего за словом (личностный смысл). Следовательно, необходимо исследовать речевое действие как 
механизм вербализаџии личностного смысла в актах функционального оперирования знаком: «если объективно знак предстоит субъекту как реальный знак со всем тем, что за ним стоит, включая и устойчивые способы оперирования с ним, то субъективно идеальная сторона знака предстает „фигурой сознания“, в которой реальное социальное содержание знака как бы смещено и преобразовано» (Леонтьев 1976: 49). Неоднократно участвуя в продуцировании речевого действия, слово начинает устойчиво ассоциироваться со своей функцией, частотная реализация которой закрепляется в виде интегративного значения слова, за которым стоят общественно одобренные способы действия (операции) со словом и ментальная форма существования предметного мира. Вне функционирования в индивидуальном сознании такие интегративные значения не психологичны: они не указывают на степень опосредования реального процесса познания значением и на то, как воплощаются языковые операции в речевой деятельности. Характер оперирования знаком представлен только в речемыслительной деятельности, и потому соотношение стимул - реакция является не только потенциальным источником новых смыслов, но и позволяет определить типологию действования со словом - установить совокупность операций с вербальными знаками в процессе ассоциирования. Ю.Н. Караулов писал, что «любое слово в нашем сознании, в памяти, точно так же, как в речевой цепи, не существует ... в отдельности: оно десятками, сотнями „нитей“ тянется к другим словам. Любое слово требует, так сказать, „продолжения“, ищет свою пару, хочет превратиться в „модель двух слов““. И такие возможные „продолжения“, такие модели двух слов - типичные, легко воспроизводимые, правдоподобные и понятные носителю языка <...> При этом каждая пара стимул—реакция - это еще не законченное высказывание, но уже необходимая его составляющая - либо грамматически оформленная его часть, либо только ядро будущего высказывания, которому предстоит придать завершенную форму» (Караулов 2002: 749).

Ассоциирование как акт предикации выявляет личностный смысл стимула, который формируется в данных конкретных условиях предикации; для субъекта последние являются условиями осмысления стимула. Но необходимо учитывать, что ассоциативное состояние - это состояние актуализации потенциальных реакций, поэтому каждая из них - вре́менная, и ее значимость для индивида надо проверять в лонгитюдном эксперименте. Следовательно, снова встает вопрос о таких параметрах ассоциирования, которые были бы устойчивыми независимо от содержания реакции. Это, во-первых, как мы показали, операщия, осуществляющая осмысление стимула, или стратегии ассоциирования - первый идентифицируемый параметр пары стимул - реакция как речевого действия. Он так или иначе отражает отношение индивида к коммуникативной ситуации.

В процессе предикации одновременно выявляется доминирующая психологическая функция языкового знака в условиях данной деятельности: фиксация свойств предметов, обнаруживающая их тождество в одном определенном отношении; обозначение знаком предмета как целого, как некоего гештальта; обобщение, когда знак представляет класс предметов и др. Эти функции актуализируют 
характер ментальных опор - понимания вербальных единиц на базе выводного знания как внутреннего источника смыслообразования речемыслительной деятельности. Ментальный «контекст прежнего переживания» - это равнозначный и «реальный» компонент актуальной речевой деятельности индивида (Голубева 2016). Методологически гносеологи и психолингвисты вполне согласны с утверждением У. Матураны и Ф. Варелы: «то, что мы принимаем как некое простое восприятие чего-то, в действительности несет на себе неизгладимую печать нашей собственной структуры» (Матурана, Варела 2001: 20); «всякое познание есть действие со стороны познающего, т.е. всякое познание зависит от структуры познающего» (Матурана, Варела 2001: 30). Но в моделях второго порядка, позволяющих анализировать процесс понимания, эта идея не реализована. Чаще актуализируется другое: «никакая живая система как отдельность не может поддержать своей внутренней динамической равновесности и не способна развиваться, если она выключена из взаимодействия, образующего более широкую систему, которая включает в себя также элементы, внешние по отношению к данной живой системе, отделенные от нее» (Леонтьев 1971: 1).

Из подхода, представленного в диссертации О.В. Голубевой, вытекают принципиально новые возможности моделирования процесса понимания и установления его специфических свойств. Эвиденциальное смысловое переживание значения единицы языка базируется на системе когнитивных ментальных опор, связанных с той или иной вербальной единицей, и определяется актуализацией ассоциативных связей между опорами не столько вследствие условий конкретной речевой деятельности, сколько вследствие содержания смыслового инварианта опор. Он оказывается стабильным ментальным источником смыслов. При этом внутренние опоры выводного знания актуализируют релевантные для данной деятельности признаки предмета деятельности, а эти признаки представлены вербально. Установить причинно-смысловые связи опор выводного знания можно, опираясь на значения языковых единиц, актуализированные в речевой деятельности. Такая связь маркируется, как утверждает О.В. Голубева, ассоциатами, возникающими на вербальные стимулы, репрезентирующие компоненты выводного знания. А значит характер ассоциата может указывать на ментальные опоры, так или иначе послужившие возникновению выводного знания (= смыслового инварианта данной деятельности). С одной стороны, благодаря такому инварианту сохраняется устойчивая направленность речевой деятельности, с другой - возможно переструктурирование смысловых опор с учетом ее мотива. Представленный смысловой инвариант системно коррелирует со словом - это экспериментально доказано в уже упомянутом исследовании О.В. Голубевой.

Понимание слова-стимула обеспечивается интеграцией ментальных данных об опыте оперирования с ним, которая специфически отражается в ассоциативносмысловом поле, дающем общее представление о переживаемом индивидом значении. Такая ментальная структура может детерминироваться системой иерархических мотивов деятельности, которые проявляются как эмоционально-оценочные компоненты значения слова (Вилюнас 1990). Мотив деятельности объективируется в ассоциативно-смысловых полях и может быть смоделирован на основе 
его маркеров (ассоциатов). Таким образом, «обнаруживается» экспликация мотива деятельности - третьего параметра в обсуждаемой модели. Смысловая близость стимулов и ассоциатов оказывается зависимой, во-первых, от сходства опыта испытуемых, во-вторых, от существенных в данной деятельности свойств объектов, названных словом-стимулом, при этом, в-третьих, испытуемые опираются в познавательной деятельности на релевантные маркеры причинно-смысловых связей опор выводного знания. Поэтому в ассоциате активируется деятельностно обусловленное содержание слова-стимула, и без субъективного процесса образования инварианта ментальных опор понимание не осуществляется. Ментальные опоры амодальны, и именно потому они порождают смысловой инвариант, хотя возникают в процессе интеграции мультимодальных компонентов восприятия.

Сказанное вполне согласуется с базовым положением методологии психолингвистики, согласно которому структура окружающей среды только «запускает» структурные изменения в мыслительной деятельности человека, но не определяет их и не управляет ими. Таким образом, содержание ассоциата, представляющего выводное знание, может стать основанием для моделирования фрагмента ассоциативно-вербальной сети индивида.

\section{4. Выводы}

Преимущества ассоциативного эксперимента в выявлении психологически актуальных для индивидов личностных смыслов определяются следующим. Он обнаруживает деятельностное отношение человека к миру, репрезентированное словом, что позволяет на основе АП моделировать характер психологической структуры содержания слова и концептуализации действительности носителями того или иного языка. Ассоциативное значение, выявляемое посредством анализа дистрибуции реакций на слово-стимул, оказывается эффективным средством обнаружения намечающихся тенденций в изменении значения слова. Только ассоциативный эксперимент дает возможность так или иначе отграничить эмоциональный, ассоциативный и референциальный компоненты значения слова. С помощью ассоциативного эксперимента обнаруживаются субъективные структурные аналогии между семантическими признаками слов-стимулов и значимыми признаками соотносимого с ним объекта действительности, включенного в деятельность с помощью стимула. Это позволяет на основе содержательного сравнения ассоциатов, представляющих одинаковый способ ассоциирования, создавать интегративные аналогические семантико-признаковые модели и выявлять не только степень расхождения между структурой семантических компонентов слова и соотношением признаков предмета, но и устанавливать операции, в которых такое расхождение частотно реализуется.

Поэтому «реальная» ассоциативная структура слова требует повышенного внимания к принципам ассоциирования, типологии реакций и их интерпретации. Однако анализ классификаций, представленный в научной литературе, свидетельствует об отсутствии общих принципов интерпретации данных ассоциативного эксперимента. 
Рассматривая, вслед за А.А. Леонтьевым, отношение стимул - реакция как речевое действие, мы предлагаем учитывать в анализе ассоциатов стратегию ассоциирования, доминирующую психологическую функцию языкового знака, реализующего стратегию, мотив деятельности, эксплицированный в ассоциатах, а также степень операционализации ассоциирования, определяемую по частотности ассоциатов, и их аксиологическую маркированность.

(C) В.А. Пищальникова, 2019 (c) commons

https://creativecommons.org/licenses/by/4.0/

\section{СПИСОК ЛИТЕРАТУРЫ / REFERENCES}

Вилюнас В.К. Психологические механизмы мотивации человека. М.: Изд-во МГУ, 1990. [Vilyunas, V.K. (1990). Psihologicheskie mekhanizmy motivacii cheloveka. Moscow: Izd-vo MGU. (In Russ.)]

Голубева О.В. Гипотеза эвиденциальности выводного знания: (экспериментальное исследование): научная монография. Тверь: Тверской гос. ун-т, 2016. [Golubeva, O.V. (2016). Gipoteza ehvidencial'nosti vyvodnogo znaniya: (ehksperimental'noe issledovanie): nauchnaya monografiya. Tver': Tverskoi gos. un-t. (In Russ.)]

Горошко Е.И. Интегративная модель свободного ассоциативного эксперимента: научная монография. Харьков: Ра-Каравелла. [Электронный ресурс]: textology.ru>razdel.aspx?ID=38. [Goroshko, E.I. Integrativnaya model' svobodnogo associativnogo eksperimenta: nauchnaya monografiya. Khar'kov: Ra-Karavella. [Elektronnyi resurs]: textology.ru^razdel.aspx?ID=38.]

Дурандина С.Л. Национальная специфика понимания концепта «человек» (на примере библейской фразеологии // Речевая деятельность. Языковое сознание. Общающиеся личности. Тезисы докладов XV Международного симпозиума по психолингвистике и теории коммуникации. М.: ИЯ РАН, РосHОУ, 2006. С. 97-98. [Durandina, S.L. (2006). Nacional'naya specifika ponimaniya koncepta «chelovek» (na primere biblejskoj frazeologii. Rechevaya deyatel'nost'. Yazykovoe soznanie. Obshchayushchiesya lichnosti. Tezisy dokladov XV Mezhdunarodnogo simpoziuma po psiholingvistike i teorii kommunikatsii. Moscow: IYA RAN, RosNOU, 97-98. (In Russ.)]

Евсеева Е.М. Концепт образа мира в языковом сознании саха и представителей американского Севера // Речевая деятельность. Языковое сознание. Общающиеся личности. Тезисы докладов XV Международного симпозиума по психолингвистике и теории коммуникации. М.: ИЯ РАН, РосHОУ, 2006. С. 99-100. [Evseeva, Е.M. (2006). Koncept obraza mira v yazykovom soznanii saha i predstavitelei amerikanskogo Severa. Rechevaya deyatel'nost'. Yazykovoe soznanie. Obshchayushchiesya lichnosti. Tezisy dokladov XV Mezhdunarodnogo simpoziuma po psiholingvistike i teorii kommunikatsii. Moscow: IYA RAN, RosNOU, 99-100. (In Russ.)]

Залевская А.А. Концепт как достояние индивида // Слово. Текст. Избранные труды. М.: Гнозис, 2005. C. 234 -244. [Zalevskaya, A.A. (2005). Koncept kak dostoyanie individa. Slovo. Tekst. Izbrannye trudy. Moscow: Gnozis, 234-244. (In Russ.)]

Залевская А.А. Телесность/корпореальность и значение слова // Языковое бытие человека и этноса: психолингвистический и когнитивный аспекты. М., Барнаул: Изд-во АлтГУ, 2004. C. 57-65. [Zalevskaya, A.A. (2004). Telesnost'/korporeal'nost' i znachenie slova. Yazykovoe bytie cheloveka i ehtnosa: psiholingvisticheskii i kognitivnyi aspekty. Moscow, Barnaul: Izd-vo AltGU, 57—65. (In Russ.)] 
Караулов Ю.Н. Активная грамматика и ассоциативно-вербальная сеть. М.: Институт русского языка PAH, 1999. [Karaulov, Yu.N. (1999). Aktivnaya grammatika i associativno-verbal'naya set'. Moscow: Institut russkogo yazyka RAN. (In Russ.)]

Караулов Ю.Н. Показатели национального менталитета в ассоциативно-вербальной цепи // Языковое сознание и образ мира. М., 2000. С. 191-206. [Karaulov, Yu.N. (2000). Pokazateli natsional'nogo mentaliteta v assotsiativno-verbal'noi tsepi. Yazykovoe soznanie i obraz mira. Moscow, 191-206. (In Russ.)]

Кинцель А.В. Экспериментальное исследование эмоционально-смысловой доминанты как текстообразующего фактора: дис. ... канд. филол. наук. Барнаул, 1998. [Kincel', A.V. (1998). Eksperimental'noe issledovanie emotsional'no-smyslovoi dominanty kak tekstoobrazuyushchego faktora. Dis. ... kand. filol. nauk. Barnaul. (In Russ.)]

Леонтьев А.А. Основы психолингвистики. М.: Смысл, 1997. [Leont'ev, А.А. (1997). Osnovy psiholingvistiki. Moscow: Smysl. (In Russ.)]

Леонтьев А.Н. Потребности, мотивы и эмоции // Психология эмоций. Тексты / под ред. В.К. Вилюнаса, Ю.Б. Гиппенрейтер. М.: Изд-во Моск. ун-та, 1984. С. 162-171. [Leont'ev, A.N. (1984). Potrebnosti, motivy i emotsii. Psihologiya emotsiy. Teksty. V.K. Vilyunasa, Yu.B. Gippenrejter (eds.). Moscow: Izd-vo Mosk. un-ta, 162-171. (In Russ.)]

Леонтьев А.А. Психолингвистические единицы и порождение речевого высказывания. М.: Наука, 1969. [Leont'ev, A.A. (1969). Psiholingvisticheskie edinitsy i porozhdenie rechevogo vyskazyvaniya. Moscow: Nauka. (In Russ.)]

Леонтьев А.А. Психолингвистический аспект языкового значения // Принципы и методы семантических исследований. М.: Наука, 1976. С. 46-73. [Leont'ev, A.A. (1976). Psiholingvisticheskiy aspekt yazykovogo znacheniya. Principy $i$ metody semanticheskih issledovaniy. Moscow: Nauka, 46-73. (In Russ.)].

Матурана У., Варела Х. Древо познания. М.: Прогресс-Традиция, 2001. [Maturana, U., Varela, H. (2001). Drevo poznaniya. Moscow: Progress-Tradiciya. (In Russ.)]

Медведева Л.П. Национально-культурная специфика речевого мышления англичан, русских и бурят (на материале домена «Игра»): дис. ... канд. филол. наук. М., 2005. [Medvedeva, L.P. (2005). Nacional'no-kul'turnaya spetsifika rechevogo myshleniya anglichan, russkih i buryat (na materiale domena «Igra»). Dis. ... kand. filol. nauk. Moscow. (In Russ.)]

Навильникова Д.И. Опыт содержательного анализа ассоциативного поля (на примере тематической группы «еда») // Вестник НГУ. Серия: Лингвистика. Т. 6. Вып. 2. С. 42-52. [Navil'nikova, D.I. Opyt soderzhatel'nogo analiza assotsiativnogo polya (na primere tematicheskoy gruppy «eda»). Vestnik NGU. Seriya: Lingvistika, 6 (2), 42-52. (In Russ.)]

Панарина Н.С. Моделирование механизма прецедентности: дис. ... канд. филол. наук. М.: МГЛУ, 2017. [Panarina, N.S. (2017). Modelirovanie mekhanizma precedentnosti. Dis. ... kand. filol. nauk. Moscow: MGLU. (In Russ.)]

Пищальникова В.А. История и теория психолингвистики. Часть 2: Этнопсихолингвистика. М.: МГЛУ, 2007. [Pishchal'nikova, V.A. (2007). Istoriya i teoriya psiholingvistiki. Chast' 2: Etnopsiholingvistika. Moscow: MGLU. (In Russ.)]

Пищальникова В.А., Сонин А.Г. Общее языкознание: учебник для студентов высших учебных заведений. М.: Р-Валент, 2012. [Pishchal'nikova, V.A., Sonin, A.G. (2012). Obshchee yazykoznanie. Moscow: R-Valent. (In Russ.)]

Русский ассоциативный словарь. В 2 т. / Ю.Н. Караулов, Г.А. Черкасова, Н.В. Уфимцева и др. M.: АСТ: Астрель, 2002. [Russkij associativnyj slovar'. V 2 t. Yu.N. Karaulov, G.A. Cherkasova, N.V. Ufimceva i dr. Moscow: AST: Astrel', 2002. (In Russ.)] 
Степанова О.В. Особенности языкового сознания немцев и русских (на материале семантического поля «Работа»: дис. ... канд. филол. наук. М.: МГЛУ, 2006. [Stepanova, O.V. (2006). Osobennosti yazykovogo soznaniya nemcev i russkih (na materiale semanticheskogo polya «Rabota»: Dis. ... kand. filol. nauk. Moscow: MGLU, 2006. (In Russ.)]

Тарасов Е.Ф. Введение. Методологические проблемы сознания // Язык и сознание: парадоксальная раииональность. М.: Ин-т яз-ния, 1993. С. 3. [Tarasov, E.F. (1993) Introduction. Methodological problems of consciousness. Language and consciousness: paradoxical rationality. Moscow: In-t yaz-niya, 1993, 3. (In Russ.)].

Уфимцева Н.В. Языковое сознание: динамика и вариативность. М.: Институт языкознания РАН, 2011. 252 c. [Ufimtseva, N. (2011). In Language consciousness: dynamics and variability. Moscow: Institute of linguistics, RAS, 2011. (In Russ.)]

Федченко А.В. Изменения в ассоциативном поле слова «любовь» в языковом сознании русских и американских подростков 11-16 лет // Язык. Сознание. Культура. Москва-Калуга: ИЯ РАН - Институт психологии РАН, 2005. С. 198-205. [Fedchenko, A.V. (2005). Izmeneniya $\mathrm{v}$ associativnom pole slova «lyubov'» $\mathrm{v}$ yazykovom soznanii russkih i amerikanskih podrostkov 11-16 let. Yazyk. Soznanie. Kul'tura. Moskva-Kaluga: IYA RAN — Institut psihologii RAN, 198 - 205. (In Russ.)]

Хлопова А.И. Вербальная диагностика динамики базовых ценностей: дис. ... канд. филол. наук. М.: МГЛУ, 2018. [Hlopova, A.I. (2018). Verbal'naya diagnostika dinamiki bazovykh tsennostey: Dis. ... kand. filol. nauk. Moscow: MGLU. (In Russ.)]

Шевченко C.Н. Структурная специфика ассоциативного поля лексических единиц, обозначающих полезные ископаемые, как проявление семантических различий лексем: дис. ... канд. филол. наук. М.: МГЛУ, 2017. [Shevchenko, S.N. (2017). Strukturnaya specifika associativnogo polya leksicheskih edinits, oboznachayushchikh poleznye iskopaemye, kak proyavlenie semanticheskikh razlichiy leksem: dis. ... kand. filol. nauk. Moscow: MGLU. (In Russ.)]

Miller, G.A., Johnson-Laird P.N. (1976). Language and Perception. Cambridge (Mass.): Harvard University Press.

\section{Article history:}

Received: 13 March2019

Revised: 29 April 2019

Accepted: 19 May 2019

\section{История статьи:}

Дата поступления в редакцию: 13 марта 2019

Дата принятия к печати: 19 мая 2019

\section{Bionote:}

VERA A. PISHCHALNIKOVA - Honored Professor of Higher Education, Doctor of Philology, Professor of the Department of General and Comparative Linguistics at Moscow State Linguistic University. Research interests: methodology of psycholinguistics, ethnopsycholinguistics, psychopetics, theory of intercultural communication.

Contact information: e-mail: pishchalnikova@mail.ru

\section{Сведения об авторе:}

ПИЩАЛЬНИКОВА ВЕРА АНАТОЛЬЕВНА - Заслуженный работник высшей школы, доктор филологических наук, профессор кафедры общего и сравнительно-исторического языкознания Московского государственного лингвистического университета. Сфера научных интересов: методология психолингвистики, этнопсихолингвистика, психопоэтика, теория межкультурной коммуникации.

Контактная информация: e-mail: pishchalnikova@mail.ru 